Article

\title{
Efficient Oxidative Esterification of Furfural Using Au Nanoparticles Supported on Group 2 Alkaline Earth Metal Oxides
}

\author{
Camila P. Ferraz ${ }^{1,2}{ }^{\circledR}$, Adriano H. Braga ${ }^{1}\left(\mathbb{D}\right.$, Mohamed Nawfal Ghazzal $^{3}$, Michał Zieliński ${ }^{4}(\mathbb{D}$,

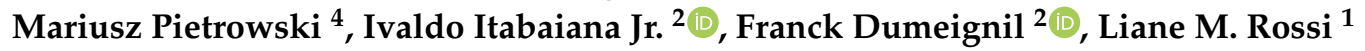 \\ and Robert Wojcieszak $2, *$ (D) \\ 1 Departamento de Química Fundamental, Instituto de Química, Universidade de São Paulo, \\ São Paulo 05508-000, Brazil; camila.ferraz@univ-lille.fr (C.P.F.); adri.hbr@gmail.com (A.H.B.); \\ lrossi@iq.usp.br (L.M.R.) \\ 2 Univ. Lille, CNRS, Centrale Lille, Univ. Artois, UMR 8181-UCCS-Unité de Catalyse et Chimie du Solide, \\ F-59000 Lille, France; ivaldo.itabaiana@univ-lille.fr (I.I.J.); Franck.dumeignil@univ-lille.fr (F.D.) \\ 3 Institut de Chimie Physique, Université Paris-Saclay, UMR 8000 CNRS, 91405 Orsay, France; \\ Mohamed-nawfal.ghazzal@universite-paris-saclay.fr \\ 4 Faculty of Chemistry, Adam Mickiewicz University in Poznań, Uniwersytetu Poznańskiego 8, \\ 61-614 Poznań, Poland; mardok@amu.edu.pl (M.Z.); mariop@amu.edu.pl (M.P.) \\ * Correspondence: robert.wojcieszak@univ-lille.fr; Tel.: +33-(03)-20-67-60-08
}

Received: 30 March 2020; Accepted: 13 April 2020; Published: 15 April 2020

check for updates

\begin{abstract}
Furfural (FF) is a strategic product for the development of highly valued chemicals from biomass. The oxidation product of FF, furoic acid (FA), is an important precursor for the synthesis of green esters, such as methyl furoate. Taking into account issues with the direct furfural oxidation, furfural derivatives, such as alkyl furoates, can be easily prepared via oxidative esterification. Here, Au nanoparticles that were immobilized on alkaline-earth metal oxide supports were studied for the oxidative esterification of furfural while using alcohol as both reactant and solvent. The formation of esters is favored by the presence of basic sites on catalyst surface, resulting in high selectivity, preventing the formation of the acetal as a by-product. The $\mathrm{Au} / \mathrm{MgO}$ sample provided up to $95 \%$ methyl furoate (MF) yield, a fast reaction rate, and high performance for furfural:Au molar ratios between 50 and 300. Furthermore, this catalyst was stable during reuse, since both the selectivity and the activity were maintained after four cycles. Oxidative esterification products were achieved in the presence of other alcohols, leading to the formation of esters of up to $\mathrm{C}_{5}$ (isopentyl furoate) with high selectivity (>99\%). Linear and branched esters were formed, but the long-chain linear alcohols resulted in higher yields, such as $n$-butyl furoate in $94 \%$ yield.
\end{abstract}

Keywords: gold nanoparticles; esterification; green oxidation; methyl furoate; biomass

\section{Introduction}

Currently, special attention has been given to the oxidation of biomass-derived substrates due to their potential to replace petroleum products [1-7]. When considering the high extent of functionality and hydrophilic properties, biomass-derived substrates should be processed in liquid phase, typically in an aqueous phase [1-4]. Thus, the development of efficient liquid phase technologies is desired, as well as catalysts working under mild conditions [1-4]. Several routes for the conversion of bio-based compounds into fuels and highly valued chemicals involve the production of furfural and 5-hydroxymethylfurfural (HMF) (Scheme 1) [8]. These are some of the products that are considered to be strategic for the development of biofuels and chemicals from biomass [8-10]. HMF is 
considered to be one of the most important platform compounds in biorefineries of the future [8-10]. Several products that are obtained via HMF oxidation are of great interest for the polymer industry because their derivatives can be used as $\mathrm{C} 6$ monomers to replace petrochemical monomers [1-10]. For example, 2,5-furandicarboxylic acid (FDCA) is a monomer in the production of polyethylene 2,5-furandicarboxylate (PEF), being a green alternative to polyethylene terephthalate (PET) [11-13]. The direct use of FDCA in the industry is difficult due to its low solubility in most commonly used solvents. The furan-2,5-dimethylcarboxylate ester (FDMC) is actually more suitable for the subsequent polymerization reaction, thanks to its better solubility. For this reason, the development of catalytic systems that are capable of producing FDMC directly from the HMF has received much attention today. One alternative is the production of FDCA can be obtained from furoic acid (furfural oxidation product) via the Henkel reaction [13]. However, the use of Au catalysts can also be a viable alternative. FDCA can be obtained from furoic acid (furfural oxidation product) via the Henkel reaction [13]. Recently, $\mathrm{Au}$ catalysts have been successfully applied for the oxidative esterification of alcohols [14-17] and they have also been explored for the esterification of furfural and HMF [18-28]. The first example of HMF esterification to produce dimethyl-2-furoate (FDMC) required the use of a base (NaOMe) [29]. Although other catalytic systems have then been reported, there are few examples of successful $\mathrm{Au}$ catalytic systems for the production of baseless FDMC. Corma et al. reported an $\mathrm{Au} / \mathrm{CeO}_{2}$ catalyst that was capable of performing the reaction in the absence of a base [8]. In comparison with other catalysts, where total conversion was observed, the observed FDMC yield followed the order $\mathrm{Au} / \mathrm{Fe}_{2} \mathrm{O}_{3}<\mathrm{Au} / \mathrm{AC}$ $<\mathrm{Au} / \mathrm{TiO}_{2} \sim \mathrm{Au} / \mathrm{CeO}_{2}$. The high performance of $\mathrm{Au} / \mathrm{CeO}_{2}$ catalyst under base free conditions inspired the development of $\mathrm{Au}$ catalysts for oxidative furfural esterification in the absence of a base [8]. Titania, ceria, and zirconia were studied by different research groups; however, Signoretto et al. revealed that the performance of catalysts in the absence of a base followed the order: $\mathrm{Au} / \mathrm{ZrO}_{2}>\mathrm{Au} / \mathrm{CeO}{ }_{2}>>$ $\mathrm{Au} / \mathrm{TiO}_{2}[30]$.

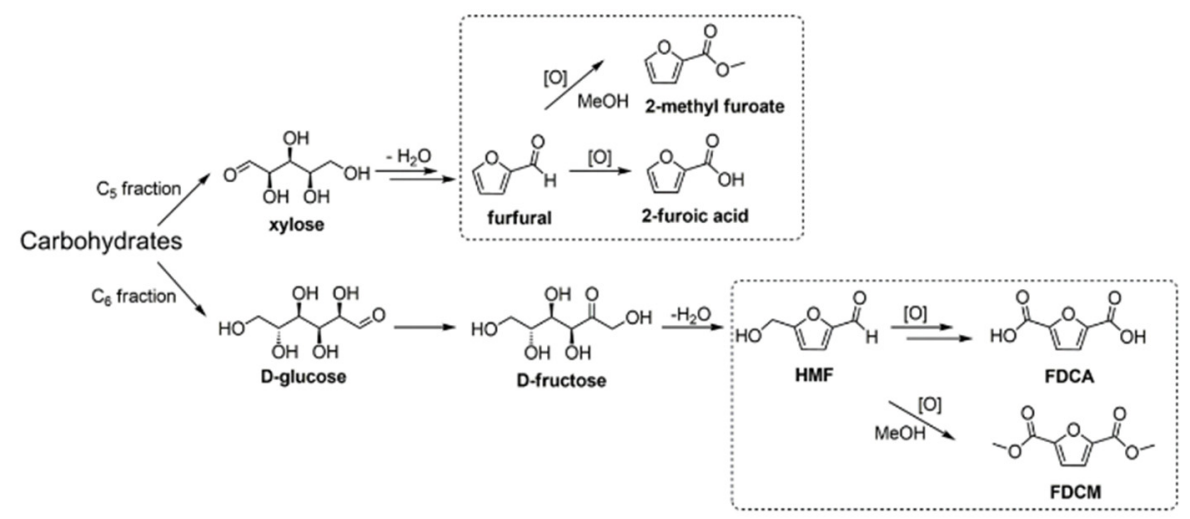

Scheme 1. Schematic representation of the synthesis procedure. Adapted with permission from [4], Copyright 2017, MDPI.

Later, $\mathrm{Au} / \mathrm{ZrO}_{2}$ was widely explored for the oxidative esterification reactions of furfural and $\mathrm{HMF}$, due to the ability of $\mathrm{ZrO}_{2}$ to provide a high dispersion of $\mathrm{Au}$ and its appropriate acid-base properties. Many parameters were also evaluated, such as the addition of dopants in the support (such as sulfates), the effect of the calcination of the support before catalyst preparation, and the calcination of the catalyst as a post-treatment step [30]. However, there is still a lack of deeper understanding of which catalytic characteristics or sites of the support are directing the reaction selectivity to ester formation at high rates. Gupta et al. [25] reported the efficient oxidative esterification of furfural with propanol to high yield methyl-2-furoate in the presence of Au hydrotalcite supported catalyst, $\mathrm{O}_{2}$, and a base $\left(\mathrm{K}_{2} \mathrm{CO}_{3}\right)$. Moreover, Kegnæs et al. studied the oxidative coupling of alcohols with $\mathrm{N}$-hexylamine to form N-hexylamides [15]. The authors found that methyl ester were formed in high yield by the furfural oxidation while using $\mathrm{Au} / \mathrm{TiO}_{2}$ and $\mathrm{KOMe}$ as a homogeneous base. However, this process 
requires a high quantity of base and it would be much greener and economic if no base would be used. The furfural oxidative esterification with methanol and without the addition of a base $\left(\mathrm{NaCH}_{3} \mathrm{O}\right)$ was also reported [31]. Gold that was supported on sulfated zirconia catalyst showed very good catalytic properties, if compared to $\mathrm{Au} / \mathrm{TiO}_{2}$ catalyst. The authors proposed that the increase in the activity of these materials was due to the presence of very small clusters of $\mathrm{Au}$, which are able to dissociate $\mathrm{O}_{2}$. This forms atomic oxygen with strong basic properties that could easily activate $\mathrm{CH}_{3} \mathrm{OH}$ and increase the reaction rates [31]. The application of gold catalysis in oxidations and oxidative esterification has grown a lot, but the issue of the use of base remains unsolved [32].

Here, we seek to evaluate Au catalysts that are supported on alkaline-earth metal oxides $(\mathrm{MgO}$, $\mathrm{CaO}, \mathrm{SrO}, \mathrm{BaO}$ ) for the oxidative esterification of furfural without the addition of a base. The results will be compared to the gold supported on non-basic supports, such as $\mathrm{TiO}_{2}, \mathrm{CeO}_{2}$, and $\mathrm{ZrO}_{2}$. Furfural esters are of high industrial importance and, moreover, the studies with furfural can also serve as a model for the oxidative esterification of HMF, which is a molecule of greater complexity.

\section{Results and Discussion}

Au-based catalysts were prepared by the pre-formed nanoparticle immobilization method (sol immobilization method) because of its reproducibility. AuPVA NPs of about $3 \mathrm{~nm}$, as determined by TEM [32], were first prepared and then supported on different metal oxides. As expected, the Au nanoparticles size was preserved after immobilization on different metal oxides, e.g. an average size of $4 \pm 0.8 \mathrm{~nm}$ was determined for all samples, as could be seen in Figure 1. When considering the same Au loading ( 2 wt. \%) and comparable Au particle size, it was expected that the catalytic performances would be mainly governed by the physicochemical properties and morphology of the support.

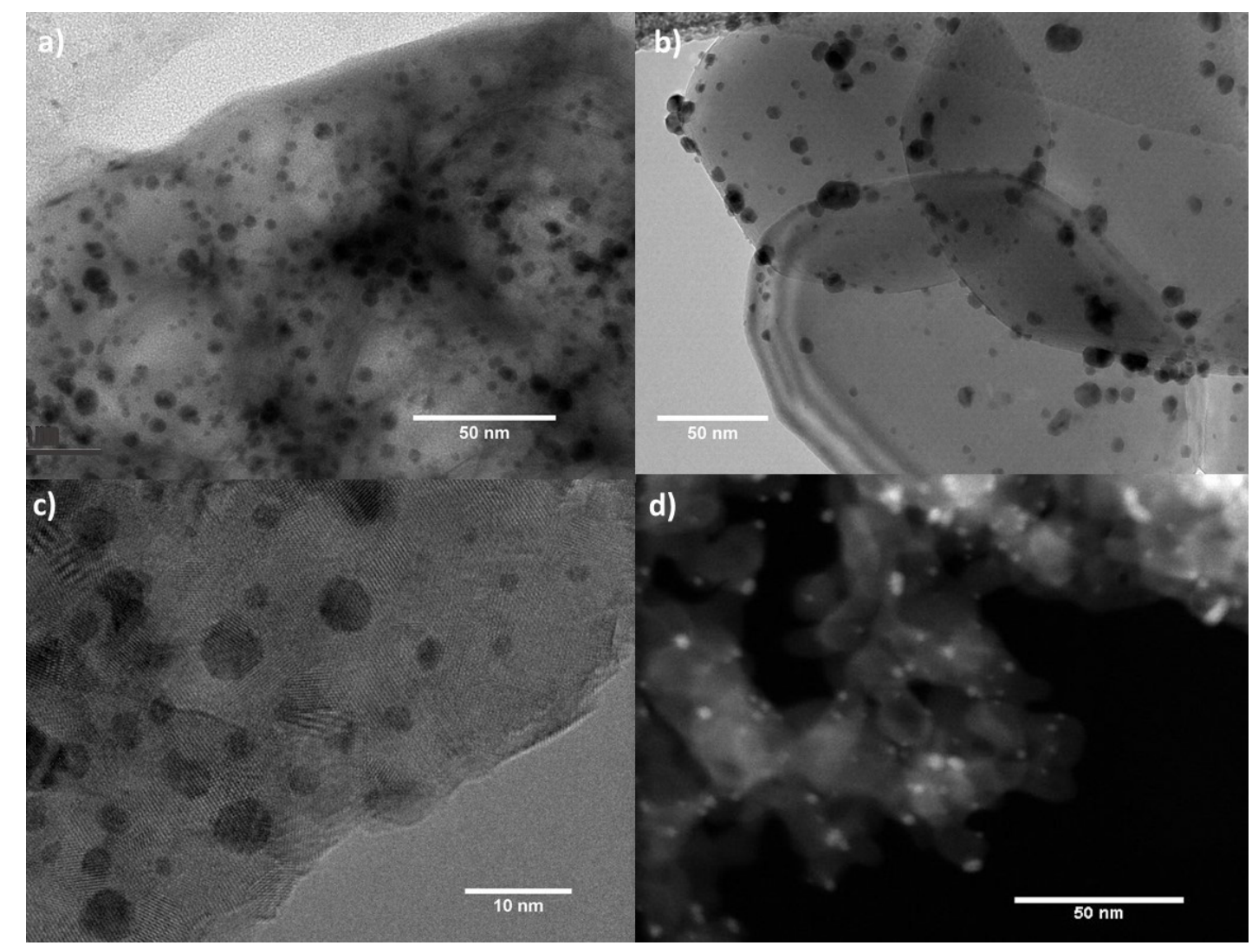

Figure 1. Transmission electron microscopy of (a) $\mathrm{Au} / \mathrm{MgO}$, (b) $\mathrm{Au} / \mathrm{SrO}$, (c) $\mathrm{Au} / \mathrm{CaO}$, and (d) $\mathrm{Au} / \mathrm{BaO}$ dark field. 
Specific surface areas of the prepared catalysts were measured while using the nitrogen physisorption method (BET). MgO showed the highest surface area of $50 \mathrm{~m}^{2} / \mathrm{g}$. CaO has a surface area of $8 \mathrm{~m}^{2} / \mathrm{g}$. BaO and $\mathrm{SrO}$ oxide supports have a very low surface area of 1 and $3.6 \mathrm{~m}^{2} / \mathrm{g}$ (Table 1 ). The specific surface area increased after the gold deposition due to the formation of polymorphous phases as confirmed by XRD studies.

Table 1. Flame Atomic Absorption Spectroscopy (FAAS) and BET results for oxides and Au-modified samples.

\begin{tabular}{|c|c|c|}
\hline Catalyst & $\mathrm{Au} \%$ (FAAS) & $\mathrm{S}_{\mathrm{BET}}\left(\mathrm{m}^{2} / \mathrm{g}\right)$ \\
\hline $\mathrm{Au}_{\mathrm{PVA}} / \mathrm{MgO}$ & 1,55 & $105.6(49.5)^{a}$ \\
\hline $\mathrm{Au}_{\mathrm{PVA}} / \mathrm{CaO}$ & 2,33 & $17.3(8.3)^{\mathrm{a}}$ \\
\hline $\mathrm{Au}_{\mathrm{PVA}} / \mathrm{BaO}$ & 3,10 & $12.4(1.2)^{\mathrm{a}}$ \\
\hline $\mathrm{Au}$ PVA/SrO & 13,10 & $-(3.6)^{a}$ \\
\hline
\end{tabular}

Table 1 depicts the catalysts characterization regarding the Au content and specific surface area. Despite the nominal amount of $\mathrm{Au}$ was 2\% wt., the real $\mathrm{Au} \%$ that was obtained by Flame Atomic Absorption Spectroscopy (FAAS) was different. This is because of the properties of these oxides that form respective hydroxides during the catalyst synthesis. Alkaline earth oxides are known to hydrate in water forming $\mathrm{M}(\mathrm{OH})_{2}$ species, which was also observed by XRD (Figure 2). However, the $\mathrm{M}(\mathrm{OH})_{2}$ are partially soluble and their solubility increase by decreasing the earth alkaline (EA) group. This could explain the increase in the Au content from Mg to Ba-catalyst, meaning that part of the support was dissolved during the synthesis. Being aware of that, $\mathrm{pH}$ corrections were performed during the synthesis, in which the $\mathrm{pH}$ of solution was adjusted to 7 prior the addition of the EA oxides for immobilization. Still, Au contents higher than $2 \%$ were observed.
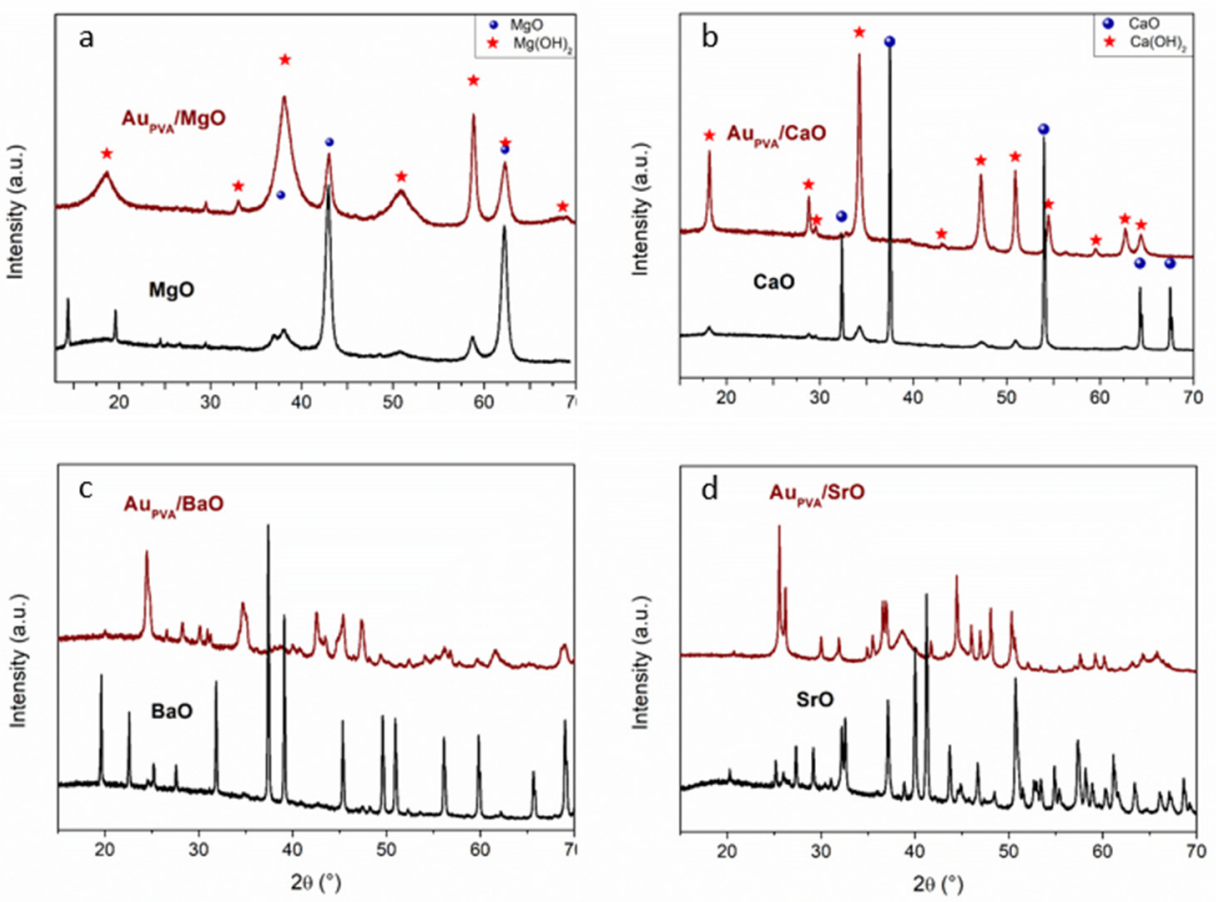

Figure 2. X-ray diffraction patterns (XRD) patterns of (a) $\mathrm{Au} / \mathrm{MgO}$, (b) $\mathrm{Au} / \mathrm{CaO}$, (c) $\mathrm{Au} / \mathrm{BaO}$, and (d) $\mathrm{Au} / \mathrm{SrO}$. 
XRD analysis revealed that the sol immobilization method induces changes in the support structure. Indeed, the diffraction peaks originating from hydroxides are present, as could be seen from the Figure 2 after preparation step. This is the case for all catalysts, but it is more pronounced for $\mathrm{MgO}$ and $\mathrm{CaO}$ oxides (Figure $2 \mathrm{a}, \mathrm{b}$ ). XRD patterns of bare $\mathrm{MgO}$ support show diffraction peaks that can be attributed to $\mathrm{MgO}$ (periclase, Ref. code 01-075-0447). The catalyst prepared by the sol immobilization method presents low crystallinity (broad reflections) of the $\mathrm{MgO}$ peaks, whereas those that originated from $\mathrm{Mg}(\mathrm{OH})_{2}$ are characterized by a more ordered structure (more intense peaks). It could be concluded that the preparation method does not result in the formation of a pure $\mathrm{MgO}$ phase. This is also the case of the $\mathrm{Au} / \mathrm{CaO}$ sample where the presence of the hydroxide phase after catalyst preparation is well visible.

Most complicated XRD patterns were observed for other oxides. Indeed, different polymorphic structures are present. The main reflections of the SrO sample can be attributed to strontianite (Ref. Code 01-084-1778) [33]. The diffraction patterns of the AU modified material exhibit reflections peaks that originate from strontianite as well as the reflections peaks originated from $\mathrm{Sr}(\mathrm{OH})_{2}$ (Ref. Code 00-019-1276) and to $\mathrm{Sr}(\mathrm{OH})_{2}\left(\mathrm{H}_{2} \mathrm{O}\right)$ (Ref.Code 01-077-2336) [33]. The very high reactivity of SrO toward water could explain the presence of these hydrated compounds [33]. The same trend is observed for barium oxide. The presence of several polymorphus phases is observed, which also confirm that the calcination temperature is not high enough to obtain pure $\mathrm{BaO}$ phase. As expected in all cases, the reflections peaks from gold nanoparticles are not observed, which confirm the small particle size, as already observed by TEM analysis.

The TPD- $\mathrm{CO}_{2}$ analysis was performed for all of the samples. However, only $\mathrm{MgO}$ oxide gave quantifiable results, as presented in Figure 3. The total quantity of basic sites was evaluated at $0.265 \mathrm{mmol}_{\mathrm{CO} 2} \cdot \mathrm{g}^{-1}$. The desorption profile was decomposed into three components (Figure 3), giving three well resolved peaks with the maximum at $112^{\circ} \mathrm{C}, 187^{\circ} \mathrm{C}$, and $285^{\circ} \mathrm{C}$. These positions corresponds to week, medium, and strong basic sites, respectively. Comparable quantity of week and strong basic sites were observed $\left(0.058\right.$ and $0.035 \mathrm{mmol}_{\mathrm{CO} 2} \cdot \mathrm{g}^{-1}$, receptivity). Contrary to that, the quantity of the medium basic sites was almost three times higher $\left(0.173 \mathrm{mmol}_{\mathrm{CO} 2} \cdot \mathrm{g}^{-1}\right)$ than that of week basic sites. The results that are obtained for other oxides are difficult to quantify. In the case of $\mathrm{CaO}$, the majority of the basic sites are with the desorption peak in the range of $550-700^{\circ} \mathrm{C}$. In the case of $\mathrm{BaO}$ and $\mathrm{SrO}$, the desorption of $\mathrm{CO}_{2}$ only starts at temperatures over $800{ }^{\circ} \mathrm{C}$ with the agreement with the literature data [33]. This strongly indicates that both $\mathrm{BaO}$ and $\mathrm{SrO}$ oxides have high predominance of the very strong basic sites. This confirms the well-known basicity strength order for alkaline earth oxides: $\mathrm{BaO}>$ $\mathrm{SrO}>\mathrm{CaO}>\mathrm{MgO}[33]$.

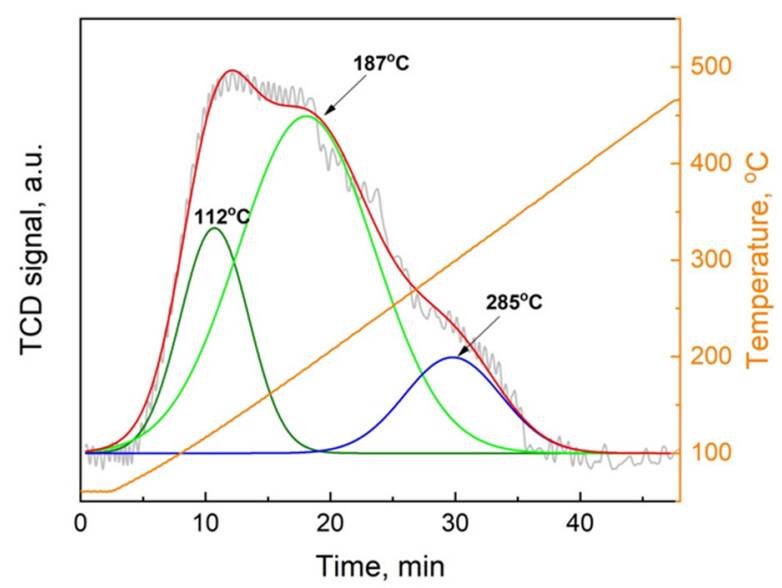

Figure 3. TPD- $\mathrm{CO}_{2}$ desorption profile obtained for $\mathrm{MgO}$ oxide.

The synthesized Au catalysts were tested in the oxidative esterification of furfural in air (reactions performed in the SPR reactor), as shown in the Figure 4. High conversions were observed for most 
of the Au catalysts and even the blank test showed more than $80 \%$ of furfural conversion. However, the yield of methyl furoate (MF) was negligible, in which dimethyl acetal furfural was the only by-product detected. With $\mathrm{Au} / \mathrm{MgO}, \mathrm{Au} / \mathrm{CaO}, \mathrm{Au} / \mathrm{NiO}$, and $\mathrm{Au} / \mathrm{BaO}$ catalysts, $\mathrm{MF}$ was formed and up to $71 \%$ selectivity to $\mathrm{MF}$ was observed for $\mathrm{Au} / \mathrm{MgO}$ sample. The presence of basic sites seem to be necessary for this reaction, since only catalysts containing basic supports $(\mathrm{MgO}, \mathrm{CaO}, \mathrm{BaO}, \mathrm{NiO})$ were effective for the oxidative esterification. Non-basic supports $\left(\mathrm{TiO}_{2}, \mathrm{CeO}_{2}, \mathrm{ZrO}_{2}\right)$ give rise to the acetalization reaction. Although oxidation occurs on the metal surface, the support also plays an important role by forming more reactive intermediates. According to Casanova et al., the hemiacetal can be converted to acetal (acetalization) or ester (oxidation), as shown in Scheme 2 [8]. A hemiacetal is formed as an intermediate that is later converted to an acetal when considering the general reaction mechanism for aldehydes reactivity. However, this is only valid when the esterification is conducted under acid conditions, otherwise the hemiacetal remains in equilibrium with the initial aldehyde (basic conditions).

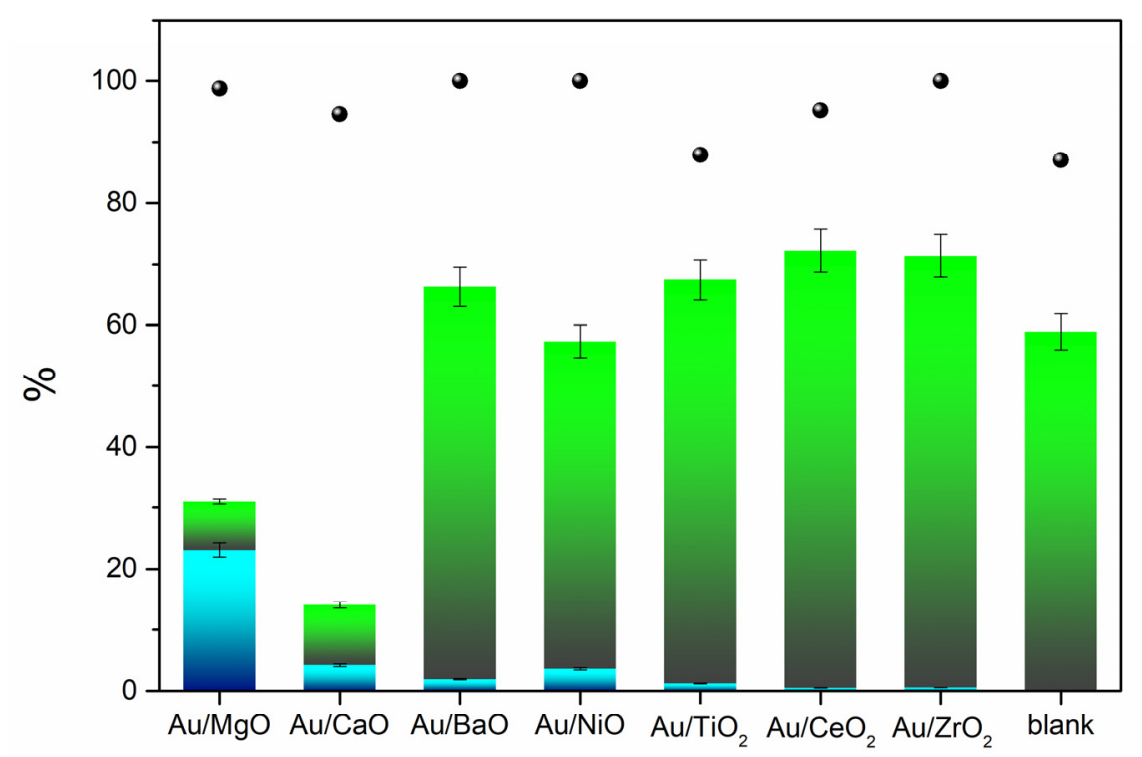

Figure 4. Oxidative esterification of furfural in methanol using Au catalyst. MF yield ( $\square$ ), acetal yield $(\square)$, carbon balance $(\bullet)$. Conditions: furfural $247 \mathrm{mmol} \mathrm{L}^{-1}$, catalyst (catalyst:substrate:MeOH = 1:500:500,000), $2 \mathrm{~h}, 110^{\circ} \mathrm{C}, 15$-bar of air, $\left.600 \mathrm{rpm}\right)$.

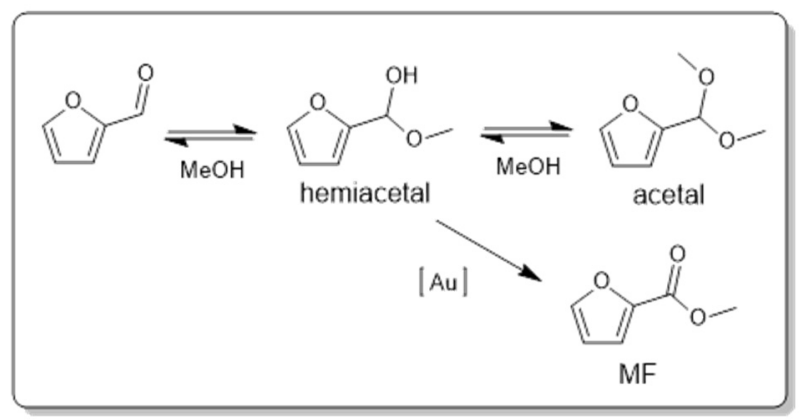

Scheme 2. Reaction pathways for furfural oxidative esterification.

The reactivity of the different Au catalysts supported on basic oxides followed the same rule; when the intermediate hemiacetal was formed, the MF was almost exclusively produced, since the basic sites do not allow for the formation of the acetal For acid sites, both pathways are possible, so the high yield of furfural acetal obtained indicates that the catalyst is more prone to acetalization than oxidation. Although conversion from acetal to ester is also possible, some authors report that this 
is unlikely to occur. When considering the homogeneous mechanism, well known for this reaction, and the obtained results, a mechanism was proposed for the reaction occurring on the surface of the Au catalyst (Scheme 3). The presence of basic sites favor the adsorption of furfural through the $\mathrm{H}_{\text {aldehyde, }}$ the resulting in the polarization of $\mathrm{H}_{\text {aldehyde }}-\mathrm{C}$ bond. The electrophilic character of carbonyl allow for the nucleophilic attack of a molecule of methanol (step 2). Subsequently, the basic site is protonated and an alkoxyde group is formed (step 3). The Au-alkoxyde bond is formed, favoring then the $\beta$-hydrogenation (step 4). Further the regeneration of the catalyst in presence of oxygen (step 5-6) is well discussed by Zope et al $[7,26]$. The presence of acid sites can also activate the $\mathrm{H}_{\text {aldehyde }}-\mathrm{C}$ bond and favor the nucleophilic attack of methanol. However, in this case, the formation of the $\mathrm{Au}_{\text {alkoxyde }}$ bond, which is crucial for the mechanism, seems unlikely. Once formed, the $\mathrm{O}_{\text {alkoxyde }}$ can more probably bond to other acid sites than to $\mathrm{Au}$.

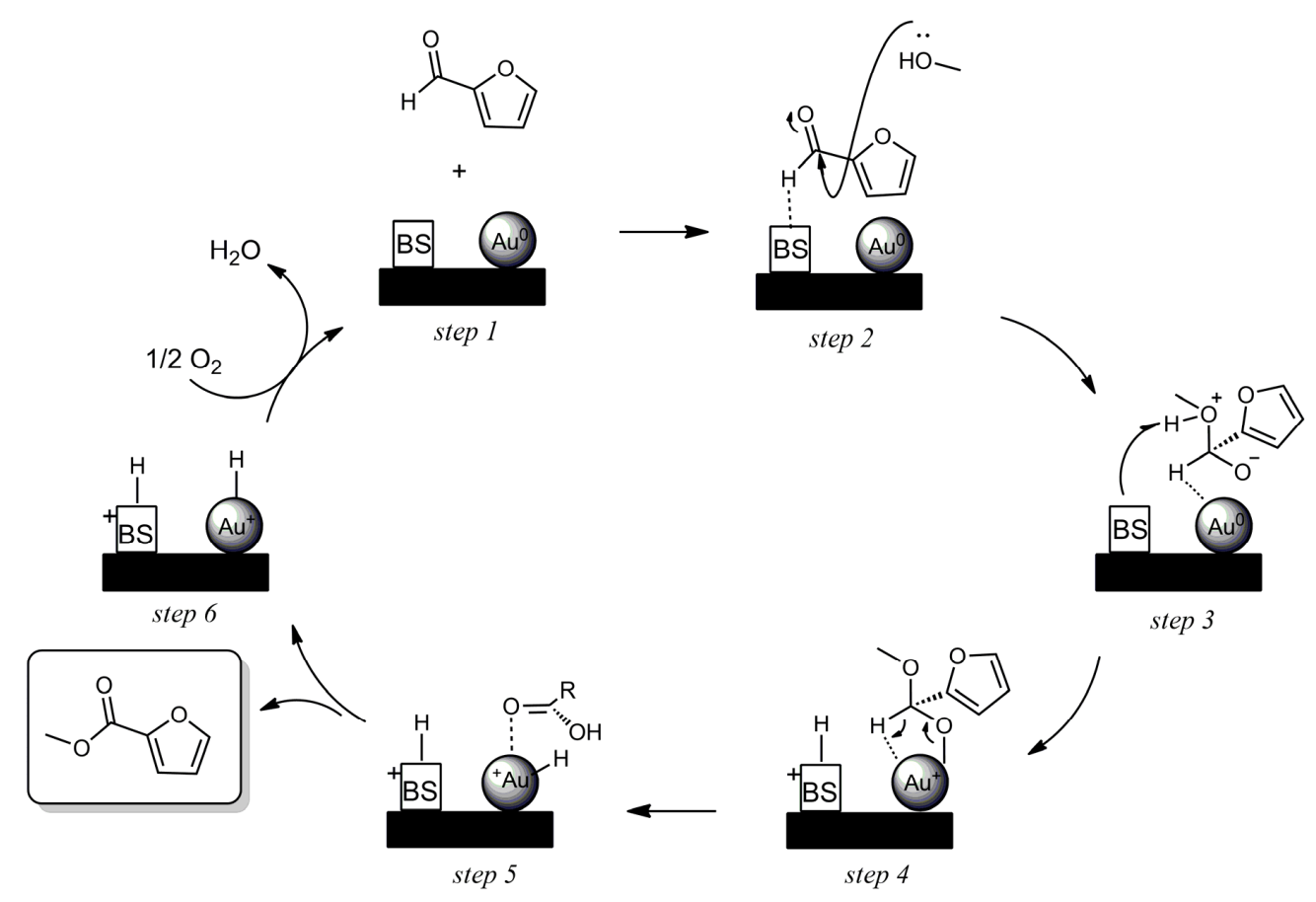

Scheme 3. Proposed mechanism for the oxidative esterification using Au-catalyst containing basic sites (BS).

These first results were encouraging and led us to study the effect of basic supports, when considering that possibly the variation of alkaline earth oxide basicity would lead us to the most active system. The higher activity that was observed for $\mathrm{Au} / \mathrm{MgO}$ motivated us to optimize the reaction conditions, where different catalyst:substrate:MeOH ratios were studied (autoclave batch reactor, as in Table 2). A higher furfural:MeOH ratio favors ester formation, since methanol is a reagent. However, the increase in the furfural:Au ratio has a more pronounced effect on activity. In all cases, the selectivity is quite high, but the furfural:Au ratio condition was chosen when considering the total conversion in the studied reaction time.

Table 2. Oxidative furfural esterification in methanol using $\mathrm{Au} / \mathrm{MgO}$ catalyst. Conditions: furfural (247 or $24.7 \mathrm{mmol} . \mathrm{L}^{-1}$ ), catalyst (18.7 mg or $187 \mathrm{mg}$ ), $2 \mathrm{~h}, 110{ }^{\circ} \mathrm{C}, 6$-bar $\mathrm{O}_{2}, 600 \mathrm{rpm}$ ).

\begin{tabular}{cccc}
\hline $\begin{array}{c}\text { Furfural: Au } \\
\text { (mol:mol) }\end{array}$ & $\begin{array}{c}\text { Furfural:MeOH } \\
\text { (mol:mol) }\end{array}$ & Conversion (\%) & $\begin{array}{c}\text { MF Yield } \\
\text { (\%) }\end{array}$ \\
\hline 50 & 1000 & 98 & 97 \\
500 & 100 & 15 & 14 \\
500 & 1000 & 25 & 22 \\
\hline
\end{tabular}


A more in-depth study was made with Au catalysts that were supported on basic oxides under these conditions (Figure 5). The Sr-based catalyst was also synthesized and tested, as a decrease in activity had already been detected when going down in the alkaline earth group $(\mathrm{Au} / \mathrm{MgO}>\mathrm{Au} / \mathrm{CaO}$ $>\mathrm{Au} / \mathrm{BaO}$ ) for furfural oxidation [32]. The results show the same trend as previously observed, thus confirming the $\mathrm{Au} / \mathrm{MgO}$ catalyst as the most active in this transformation. However, under these conditions, acetal was not observed and, therefore, selectivities to MF of at least $80 \%$ were obtained for alkaline-earth oxide-based catalysts. These results suggest that the basic sites present in these oxides are essential in directing the reaction path to the formation of the ester. Later studies with $\mathrm{Au} / \mathrm{MgO}$ showed a very fast reaction kinetics, as shown in Figure 6a, in which complete conversion was observed in only $30 \mathrm{~min}$. with high MF yield $(>90 \%)$. Furthermore, regarding the substrate:metal ratio, higher furfural:Au ratios can be used with high MF yields (Figure 6b), while a decrease of activity was observed for furfural:Au ratios that were higher than 300. However, the selectivity remained high in all ratios studied, highlighting the specificity of this transformation.

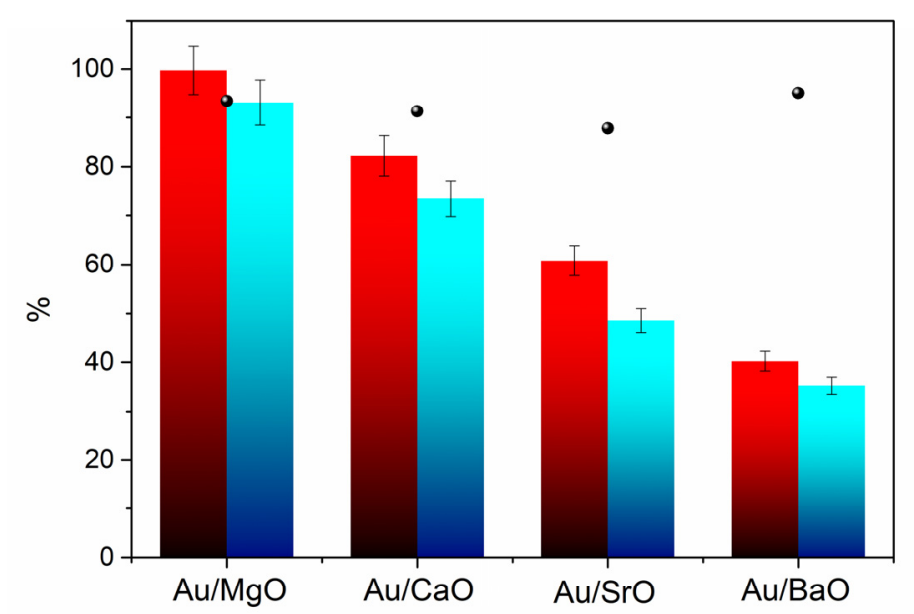

Figure 5. Oxidative esterification of furfural in methanol using Au catalyst. Conversion ( $\square$ ), methyl furoate $(\mathrm{MF})$ yield $(\square)$, carbon balance $(\bullet)$. Conditions: furfural $24.7 \mathrm{mmol} \mathrm{L}^{-1}$, catalyst (catalyst:substrate:MeOH = 1:50:50,000), $2 \mathrm{~h}, 110{ }^{\circ} \mathrm{C}, 6-$ bar $\mathrm{O}_{2}, 600 \mathrm{rpm}$ ).

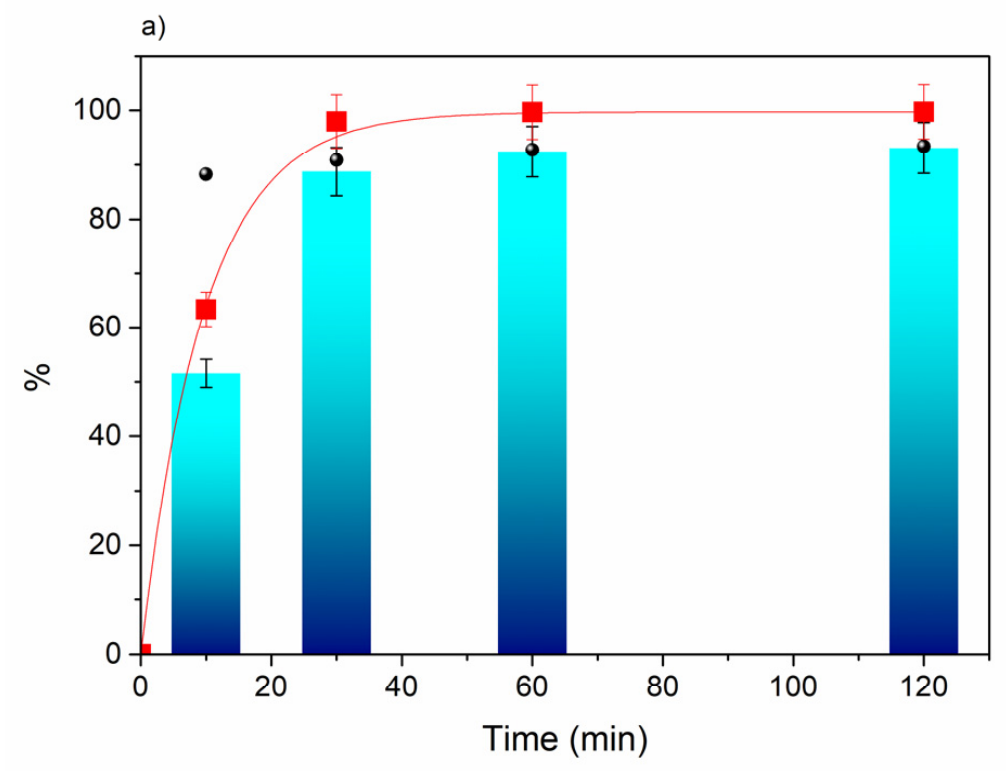

Figure 6. Cont. 


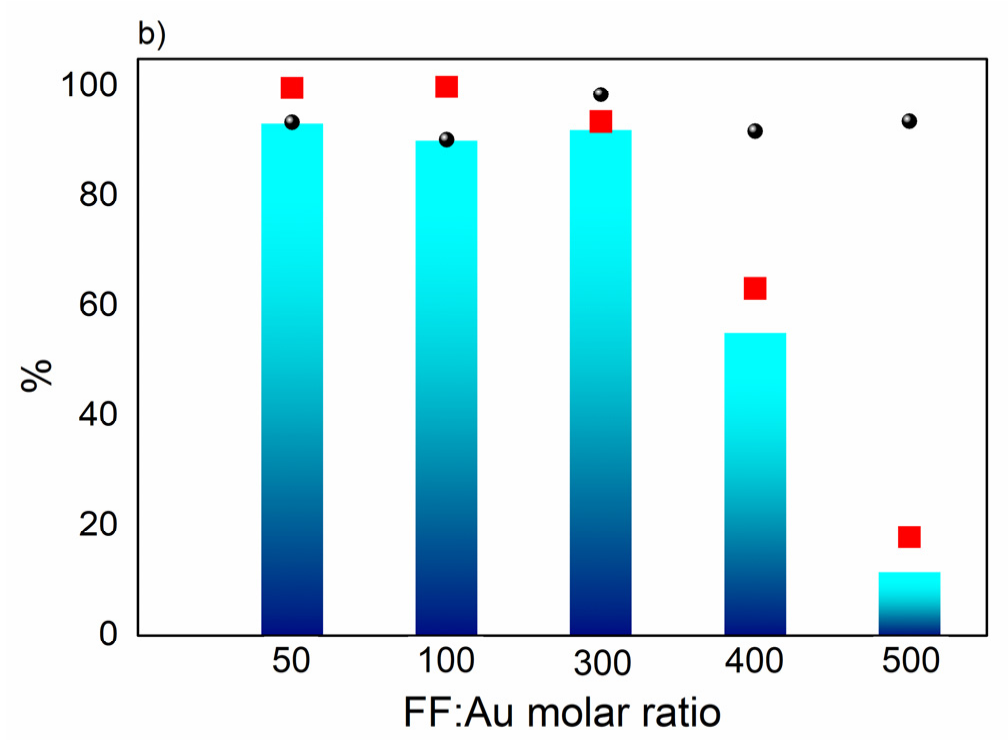

Figure 6. Oxidative esterification of furfural in methanol using $\mathrm{Au} / \mathrm{MgO}$ : conversion and yield of $\mathrm{MF}$ as a function of the reaction time using furfural:Au $=50(\mathbf{a})$, and as a function of the furfural:Au ratio after $2 \mathrm{~h}$ of reaction (b). Conversion ( $\square$ ), MF yield ( $\square$ ), carbon balance $(\bullet)$. Conditions: furfural $24.7 \mathrm{mmol} \mathrm{L}^{-1}$, catalyst (catalyst:substrate: $\mathrm{MeOH}=1: 50: 50,000$ ), $110{ }^{\circ} \mathrm{C}, 6-\mathrm{bar} \mathrm{O}_{2}, 600 \mathrm{rpm}$.

Recycling experiments were examined for the oxidative esterification of furfural using the following conditions: furfural: $\mathrm{Au}=50$ and $15 \mathrm{~min}$. reaction while using the $\mathrm{Au} / \mathrm{MgO}$ catalyst (Figure 7). After the first reaction, the catalyst was recovered by centrifugation of the reaction mixture. The products were collected with a syringe and the recovered catalyst was washed with ethanol $(2 \mathrm{~mL})$ and then dried at $80^{\circ} \mathrm{C}$ for $2 \mathrm{~h}$. The reused catalyst was weighed and used in successive oxidation reactions, adding new portions of solvent and substrate. This procedure was repeated four times, however the $\mathrm{Au} / \mathrm{MgO}$ catalyst increased its activity after the first cycle, when considering the same reaction time. After the first cycle, the furfural conversion went from 64 to $80 \%$, while the selectivity to MF was maintained at $84 \%$, resulting in $70 \%$ MF yield, as shown in Figure 7 . The catalyst did not undergo deactivation process, on the contrary, $\mathrm{Au} / \mathrm{MgO}$ was more active after reuse and its catalytic activity remains the same, even after the $4^{\text {th }}$ reuse. This might be related to the removal of part of the PVA that acts as a stabilizer for Au NPs. Stabilizers can block access to specific sites on the catalyst surface and, therefore, some authors report the removal of these stabilizers by several techniques (calcination, $\mathrm{O}_{2}$ treatment, solvent washing) in order to improve the catalytic performance of catalysts prepared from pre-formed nanoparticles. However, the reaction condition itself might represent a stabilizer washing treatment, since the catalyst remains at a higher temperature of $100{ }^{\circ} \mathrm{C}$ in methanol and under agitation. Additionally, the fact that this activity is maintained in the other cycles rules out any leaching or metal loss.

The high activity of this Au catalyst motivated us to study the efficiency of the oxidative esterification reaction while using other alcohols, from long and branched carbon chains ones. The reaction was slower in the presence of these alcohols and, therefore, the catalytic tests were run for $15 \mathrm{~h}$ and furfural ratio: $\mathrm{Au}=50$ (Table 3). 


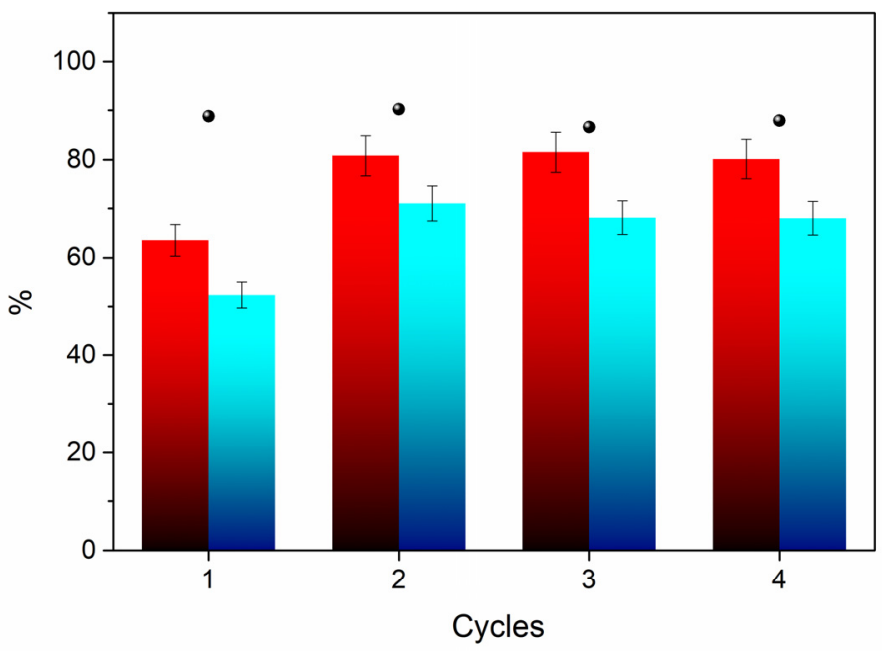

Figure 7. Oxidative esterification of furfural in methanol using $\mathrm{Au} / \mathrm{MgO}$ : reuse of the catalyst. Conversion ( $\square$ ), MF yield $(\square)$, carbon balance $(\bullet)$. Conditions: furfural $24.7 \mathrm{mmol} \mathrm{L}^{-1}$, catalyst (catalyst:substrate:MeOH = 1:50:50,000), 15 min., $110{ }^{\circ} \mathrm{C}, 6$-bar of $\mathrm{O}_{2}, 600 \mathrm{rpm}$ ).

Table 3. Oxidative esterification of furfural in ethanol (EtOH), isopropanol (i-PrOH), n-butanol (n-ButOH) and isopentanol (i-PentOH) using $\mathrm{Au} / \mathrm{MgO}$. Conditions: furfural $24.7 \mathrm{mmol} \mathrm{L}^{-1}$, catalyst (catalyst:substrate: $\mathrm{MeOH}=1: 50: 50,000), 15 \mathrm{~h}, 110{ }^{\circ} \mathrm{C}, 6$-bar of $\mathrm{O}_{2}, 600 \mathrm{rpm}$ ).

Entry

Oxidative esterification in the presence of ethanol (EthOH, Table 3, entry 1), isopropanol (i-PrOH, Table 3, entry 2), n-butanol (n-ButOH, Table 3, entry 3), and isopentanol (i-PentOH, Table 3, entry 4) was also successful, leading to the formation of the corresponding esters (ethyl-, isopropyl-, n-butyl-, and isopentyl furoates). The respective esters were formed with high selectivity ( $>99 \%)$, and the linear and long carbon chain alcohols provided the highest yields, as is the case of the n-butyl furoate that formed with $92 \%$ yield. Branched alcohols represent a higher steric hindrance when compared to linear alcohols and, therefore, esterification in this case is more difficult. Long-chain alcohols also allow for higher conversion, even though they present less nucleophilicity when compared to short-chain alcohols. 


\section{Materials and Methods}

\subsection{Materials}

Chloroauric acid trihydrate $\left(\mathrm{HAuCl}_{4} \cdot 3 \mathrm{H}_{2} \mathrm{O}, 99.9 \%\right.$, Sigma-Aldrich, Saint Louis, MO, USA), sodium borohydride $\left(\mathrm{NaBH}_{4}, 98 \%\right.$, Sigma-Aldrich, Saint Louis, MO, USA), poly(vinyl alcohol) (PVA, Sigma-Aldrich, Saint Louis, MO, USA, MW 55,000 g/mol), sodium citrate $\left(\mathrm{Na}_{3} \mathrm{C}_{6} \mathrm{H}_{5} \mathrm{O}_{7}\right.$, 99\%, Sigma-Aldrich, Saint Louis, MO, USA), furfural $\left(\mathrm{C}_{5} \mathrm{H}_{4} \mathrm{O}_{2},>99 \%\right.$, Sigma-Aldrich, Saint Louis, MO, USA), 5-hydroxymethylfurfural (HMF, 99\%, Sigma-Aldrich, Saint Louis, MO, USA), furoic acid (FA, 99\%, Sigma-Aldrich, Saint Louis, MO, USA), 5-hydroxymethyl-2-furancarboxylic acid (HMFCA, $>99 \%$, Sigma-Aldrich, Saint Louis, MO, USA), 2,5-diformylfuran (DFF, >99\%, Sigma-Aldrich, Saint Louis, MO, USA), 5-formyl-2-furoic acid (FFCA, $>99 \%$, Sigma-Aldrich, Saint Louis, MO, USA), and 2,5-furandicarboxylic acid (FDCA, 99\%, Sigma-Aldrich, Saint Louis, MO, USA) were of analytical grade and used as received. Deionized water $(18.2 \mathrm{M} \Omega)$ was used for the preparation of all the needed solutions. $\mathrm{MgO}$ and Cao were commercial oxides that were purchased from Sigma-Aldrich, Saint Louis, MO, USA ( $<99 \%)$. $\mathrm{BaO}$ and $\mathrm{SrO}$ were synthetized by thermal decomposition of nitrate salts at $700{ }^{\circ} \mathrm{C}$.

\subsection{Synthesis of $A u$ Based Catalysts}

The Au nanoparticles were prepared according to the literature [2,3]. A $2 \%$ polyvinyl alcohol (PVA) solution was added to an aqueous solution of $\mathrm{HAuCl}_{4}\left(5 \times 10^{-4} \mathrm{~mol} \mathrm{~L}^{-1}\right)$ under vigorous stirring $\mathrm{PVA} / \mathrm{Au}(\mathrm{w} / \mathrm{w})=1.2)$; to this solution a freshly prepared $0.1 \mathrm{~mol} \mathrm{~L}^{-1} \mathrm{NaBH}_{4}$ solution $\left(\mathrm{NaBH}_{4} / \mathrm{Au}(\mathrm{mol} / \mathrm{mol})=5\right)$ was then added, forming a reddish colloid (Au nanoparticles). After $30 \mathrm{~min}$., the nanoparticles were immobilized by the addition of support $\left(\mathrm{MgO}, \mathrm{CaO}, \mathrm{SrO}, \mathrm{BaO}, \mathrm{NiO}, \mathrm{TiO}_{2}\right.$, $\mathrm{CeO}_{2}$, and $\mathrm{ZrO}_{2}$ ) under vigorous agitation. The amount of support was calculated to result in a final metal loading of $2 \mathrm{wt} \%$ (nominal). After $2 \mathrm{~h}$, the mixture was filtered and the solid was washed with $60{ }^{\circ} \mathrm{C}$ Milli-Q water $(2 \times 25 \mathrm{~mL})$ and ethanol $(2 \times 25 \mathrm{~mL})$ and then dried at $100{ }^{\circ} \mathrm{C}$ for $1 \mathrm{~h}$.

\subsection{Oxidative Esterification Reactions of Furfural}

Some of the reactions were performed using the Freeslate MultiReactor available on the REALCAT EQUIPEX platform at Centrale Lille. It consists of 24 parallel batch reactors for high performance screening, in which each reactor was loaded with a furfural methanolic solution $\left(2 \mathrm{~mL}, 247 \mathrm{mmol} \mathrm{L}^{-1}\right)$ and the Au based catalyst (10 mg, $0.9 \mu \mathrm{mol}$ of metal). The reaction was performed at 20-bar of air (final pressure $26 \mathrm{bar}$ ), $110^{\circ} \mathrm{C}, 600 \mathrm{rpm}, 2 \mathrm{~h}$. Some reactions were performed in a TopIndustry (Vaux le Penil, France) autoclave reactor. The reactor was loaded with a furfural methanolic solution $(20 \mathrm{~mL}, 24.7$ or $247 \mathrm{mmol} \mathrm{L}^{-1}$ ) and the Au based catalyst $(100 \mathrm{mg}, 9 \mu \mathrm{mol}$ of metal). The reaction was performed at 6-bar of $\mathrm{O}_{2}, 110{ }^{\circ} \mathrm{C}, 600 \mathrm{rpm}$, at different reaction times, from two to six hours. In both cases, after the reaction, the catalyst was removed by filtration, the liquid products were diluted in methanol and analyzed by gas chromatography. The analysis of the products was performed in a gas chromatograph that was equipped with a CARBOWAX column for the analysis of furfural and reaction products.

\subsection{Characterization}

The Flame Atomic Absorption Spectroscopy (FAAS) method was used to determine the amount of metal deposited on the oxides. The samples that were digested in aqua regia analyzed on Shimadzu AA-6300 atomic absorption spectrometer (Columbia, MD, USA).

The ICP-OES (Inductively Coupled Plasma Optical Emission Spectrometry) analysis was performed using Agilent 720-ES ICP-OES equipment (Santa Clara, CA, USA) combined with Vulcan $42 \mathrm{~S}$ automated digestion system.

The powder X-ray diffraction patterns (XRD) were recorded with a Bruker AXS D8 Advance diffractometer (Billerica, MA, USA). The samples were scanned at $0.014^{\circ} \mathrm{s}^{-1}$ over the range $20 \leq 2 \theta \leq 80^{\circ}$. 
The (BET) specific surface areas measurements were determined by $\mathrm{N}_{2}$ adsorption at $-196{ }^{\circ} \mathrm{C}$ while using a Micromeritics ASAP 2010 sorptometer (Norcross, GA, USA).

Transmission Electron Microscopy (TEM) images were recorded placing a drop of the particles dispersion in isopropanol over a carbon film supported on a cooper grid. FEI Tecnai microscope (Hillsboro, Ore. USA) was used for the recording of the images.

TPD- $\mathrm{CO}_{2}$ was carried out on a Micromeritics ChemiSorb 2705 (Norcross, GA, USA). Before the $\mathrm{CO}_{2}$ adsorption, the samples were pre-treated in situ in $\mathrm{He}$ at $500^{\circ} \mathrm{C}$ for $30 \mathrm{~min} . \mathrm{CO}_{2}$ was adsorbed at $50{ }^{\circ} \mathrm{C}$ for $1 \mathrm{~h}$. TPD-CO $\mathrm{CO}_{2}$ measurements were performed in the temperature range of $50-700{ }^{\circ} \mathrm{C}$ while using a ramp rate of $10^{\circ} \mathrm{C} \mathrm{min}^{-1}$. A thermal conductivity detector (TCD) was used for the quantification of the desorbed $\mathrm{CO}_{2}$.

\section{Conclusions}

Methyl furoate (MF) was directly produced from furfural with supported Au-based catalysts in the absence of a base. Initial studies indicated that support basic sites are essential for promoting catalytic selectivity to ester, since catalysts that were based on basic oxides were the most effective. Studies on the oxidative esterification of furfural in methanol with $\mathrm{Au} / \mathrm{MgO}$ allowed for optimizing reaction parameters, such as furfural:Au and furfural:methanol ratios. Thus, $100 \%$ furfural conversion could be obtained with only $30 \mathrm{~min}$. reaction time and up to $95 \%$ yield of methyl furoate was obtained. This suggests a very active catalyst with a fast reaction kinetics, which allows for the use of higher furfural:Au ratios. In this case, total furfural conversion to methyl furoate was achieved with ratios up to 300 and MF yield higher than $90 \%$. This catalyst was highly selective in all tests and stable under reuse conditions (up to four cycles), also allowing for its use for the oxidative esterification of furfural with other alcohols. The selectivity for esters was greater than $99 \%$ in all cases (esters of linear and branched carbon chain alcohols were formed). Linear and long-chain alcohols resulted in higher yields, such as n-butyl furoate that was obtained with $94 \%$ yield. Studies with furfural can serve as a model for the oxidative esterification of HMF, which is a molecule of higher complexity, thus opening the possibility of extending its applicability.

Author Contributions: Conceptualization, C.P.F., L.M.R. and R.W.; methodology, C.P.F. and A.H.B.; writing—original draft preparation, C.P.F; N.M.G.; M.P., M.Z. and R.W.; writing—review and editing, C.P.F; R.W.; M.N.G.; I.I.J.; L.M.R. and F.D.; visualization, M.P.; M.Z.; I.I.J. and F.D.; supervision, R.W. and L.M.R.; project administration, C.P.F. and L.M.R.; funding acquisition, L.M.R. All authors have read and agreed to the published version of the manuscript.

Funding: This research was funded by Fundação de Amparo à Pesquisa do Estado de São Paulo (FAPESP), grant number 2014/10824-3 2017/03235-0, 2014/15159-8.

Acknowledgments: The authors acknowledged CNPq, CAPES and FAPESP (grant \# 2014/10824-3 and 2014/15159-8) for the financial support. The REALCAT platform is benefiting from a state subsidy administrated by the French National Research Agency (ANR) within the frame of the 'Investments for the Future' program (PIA), with the contractual reference 'ANR-11-EQPX-0037'. The European Union, through the FEDER funding administered by the Hauts-de-France Region, has co-financed the platform. Centrale Lille, CNRS, and the University of Lille as well as the Centrale Initiatives Foundation, are thanked for their financial contributions to the acquisition and implementation of the equipment of the REALCAT platform. This study was supported by the French government through the Programme Investissement d'Avenir (I-SITE ULNE / ANR-16-IDEX-0004 ULNE) managed by the Agence Nationale de la Recherche. LIA CNRS France-Brazil "Energy \& Environment" and Métropole Européen de Lille (MEL) for "CatBioInnov" project are also acknowledged.

Conflicts of Interest: The authors declare no conflict of interest.

\section{References}

1. Chheda, J.N.; Huber, G.W.; Dumesic, J.A. Liquid-phase catalytic processing of biomass-derived oxygenated hydrocarbons to fuels and chemicals. Angew. Chem. Int. Ed. 2007, 46, 7164-7183. [CrossRef] [PubMed]

2. Corma, A.; Iborra, S.; Velty, A. Chemical Routes for the Transformation of Biomass into Chemicals. Chem. Rev. 2007, 107, 2411-2502. [CrossRef] [PubMed] 
3. Dumeignil, F.; Capron, M.; Katryniok, B.; Wojcieszak, R.; Löfberg, A.; Girardon, J.-S.; Desset, S.; Araque-Marin, M.; Jalowiecki-Duhamel, L.; Paul, S. Biomass-derived Platform Molecules Upgrading through Catalytic Processes: Yielding Chemicals and Fuels. J. Jpn. Pet. Inst. 2015, 58, 257-273. [CrossRef]

4. Wojcieszak, R.; Ferraz, C.P.; Sha, J.; Houda, S.; Rossi, L.M.; Paul, S. Advances in Base-Free Oxidation of Bio-Based Compounds on Supported Gold Catalysts. Catalysts 2017, 7, 352. [CrossRef]

5. Lolli, A.; Albonetti, S.; Utili, L.; Amadori, R.; Ospitali, F.; Lucarelli, C.; Cavani, F. Insights into the reaction mechanism for 5-hydroxymethylfurfural oxidation to FDCA on bimetallic Pd-Au nanoparticles. Appl. Catal. A Gen. 2015, 504, 408-419. [CrossRef]

6. Ferraz, C.P.; Costa, J.S.N.; Teixeira-Neto, E.; Teixeira-Neto, A.; Liria, C.W.; Thuriot-Roukos, J.; Mancini, T.M.; Froidevaux, R.; Dumeignil, F.; Rossi, M.L.; et al. 5-hydroxymenylfurfural and furfural base-free oxidation over AuPd embedded bimetallic nanoparticles. Catalysts 2020, 10, 75. [CrossRef]

7. Zope, B.N.; Hibbitts, D.D.; Neurock, N.; Davis, R.J. Reactivity of the gold/water interface during selective oxidation catalysis. Science 2010, 330, 74-78. [CrossRef]

8. Casanova, O.; Iborra, S.; Corma, A. Biomass into chemicals: Aerobic oxidation of 5-hydroxymethyl-2-furfural into 2,5-furandicarboxylic acid with gold nanoparticle catalyst. ChemSusChem 2009, 2, 1138-1144. [CrossRef]

9. Teong, S.P.; Yi, G.; Zhang, Y. Hydroxymethylfurfural production from bioresources: Past, present and future. Green Chem. 2014, 16, 2015-2026. [CrossRef]

10. Van Putten, R.-J.; van der Waal, J.C.; de Jong, E.; Rasrendra, C.B.; Heeres, H.J.; de Vries, J.G. Hydroxymethylfurfural, a versatile platform chemical made from renewable resources. Chem. Rev. 2013, 113, 1499-1597. [CrossRef]

11. De Jong, E.; Dam, M.A.; Sipos, L.; Gruter, G.-J.M. Furandicarboxylic Acid (FDCA), A Versatile Building Block for a Very Interesting Class of Polyesters, ACS Symposium Series; American Chemical Society: Washington, DC, USA, 2012; pp. 1-13.

12. Zhang, J.; Li, J.; Tang, Y.; Lin, L.; Long, M. Advances in catalytic production of bio-based polyester monomer 2,5-furandicarboxylic acid derived from lignocellulosic biomass. Carbohydr. Polym. 2015, 130, 420-428. [CrossRef] [PubMed]

13. Wojcieszak, R.; Itabaina, I. Engineering the future: Perspectives in the 2,5-furandicarboxylic acid synthesis. Catal. Today 2020. [CrossRef]

14. Nielsen, I.S.; Taarning, E.; Egeblad, K.; Madsen, R.; Christensen, C.H. Direct aerobic oxidation of primary alcohols to methyl esters catalyzed by a heterogeneous gold catalyst. Catal. Lett. 2007, 116, 35-40. [CrossRef]

15. Gallas-Hulin, A.; Kotni, R.K.; Nielsen, M.; Kegnæs, S. Catalytic Oxidation of Allylic Alcohols to Methyl Esters. Top. Catal. 2017, 60, 1380-1386. [CrossRef]

16. Whiting, G.T.; Kondrat, S.A.; Hammond, C.; Dimitratos, N.; He, Q.; Morgan, D.J.; Dummer, N.F.; Bartley, J.K.; Kiely, C.J.; Taylor, S.H.; et al. Methyl Formate Formation from Methanol Oxidation Using Supported Gold-Palladium Nanoparticles. ACS Catal. 2015, 5, 637-644. [CrossRef]

17. Oliveira, R.L.; Kiyohara, P.K.; Rossi, L.M. Clean preparation of methyl esters in one-step oxidative esterification of primary alcohols catalyzed by supported gold nanoparticles. Green Chem. 2009, 11, 1366-1370. [CrossRef]

18. Albonetti, S.; Lolli, A.; Morandi, V.; Migliori, A.; Lucarelli, C.; Cavani, F. Conversion of 5-hydroxymethylfurfural to 2,5-furandicarboxylic acid over Au-based catalysts: Optimization of active phase and metal-support interaction. Appl. Catal. B Environ. 2015, 163, 520-530. [CrossRef]

19. Miao, Z.; Zhang, Y.; Pan, X.; Wu, T.; Zhang, B.; Li, J.; Yi, T.; Zhang, Z.; Yang, X. Superior catalytic performance of $\mathrm{Ce} 1-\mathrm{xBixO} 2-\delta$ solid solution and $\mathrm{Au} / \mathrm{Ce} 1-\mathrm{xBixO} 2-\delta$ for 5-hydroxymethylfurfural conversion in alkaline aqueous solution. Catal. Sci. Technol. 2015, 5, 1314-1322. [CrossRef]

20. Cai, J.; Ma, H.; Zhang, J.; Song, Q.; Du, Z.; Huang, Y.; Xu, J. Gold Nanoclusters Confined in a Supercage of Y Zeolite for Aerobic Oxidation of HMF under Mild Conditions. Chem. Eur. J. 2013, 19, 14215-14223. [CrossRef]

21. Gorbanev, Y.Y.; Klitgaard, S.K.; Woodley, J.M.; Christensen, C.H.; Riisager, A. Gold-Catalyzed Aerobic Oxidation of 5-Hydroxymethylfurfural in Water at Ambient Temperature. ChemSusChem 2009, 2, 672-675. [CrossRef]

22. Davis, S.E.; Houk, L.R.; Tamargo, E.C.; Datye, A.K.; Davis, R.J. Oxidation of 5-hydroxymethylfurfural over supported Pt, Pd and Au catalysts. Catal. Today 2011, 160, 55-60. [CrossRef] 
23. Ardemani, L.; Cibin, G.; Dent, A.J.; Isaacs, M.A.; Kyriakou, G.; Lee, A.F.; Parlett, C.M.A.; Parry, S.A.; Wilson, K. Solid base catalysed 5-HMF oxidation to 2,5-FDCA over Au/hydrotalcites: Fact or fiction? Chem. Sci. 2015, 6, 4940-4945. [CrossRef] [PubMed]

24. Gao, T.; Gao, T.; Fang, W.; Cao, Q. Base-free aerobic oxidation of 5-hydroxymethylfurfural to 2,5-furandicarboxylic acid in water by hydrotalcite-activated carbon composite supported gold catalyst. Mol. Catal. 2017, 439, 171-179. [CrossRef]

25. Gupta, N.K.; Nishimura, S.; Takagaki, A.; Ebitani, K. Hydrotalcite-supported gold-nanoparticle-catalyzed highly efficient base-free aqueous oxidation of 5-hydroxymethylfurfural into 2,5-furandicarboxylic acid under atmospheric oxygen pressure. Green Chem. 2011, 13, 824-827. [CrossRef]

26. Zope, B.N.; Davis, S.E.; Davis, R.J. Influence of Reaction Conditions on Diacid Formation During Au-Catalyzed Oxidation of Glycerol and Hydroxymethylfurfural. Top. Catal. 2012, 55, 24-32. [CrossRef]

27. Wan, X.; Zhou, C.; Chen, J.; Deng, W.; Zhang, Q.; Yang, Y.; Wang, Y. Base-Free Aerobic Oxidation of 5-Hydroxymethyl-furfural to 2,5-Furandicarboxylic Acid in Water Catalyzed by Functionalized Carbon Nanotube-Supported Au-Pd Alloy Nanoparticles. ACS Catal. 2014, 4, 2175-2185. [CrossRef]

28. Zhang, Z.; Deng, K. Recent Advances in the Catalytic Synthesis of 2,5-Furandicarboxylic Acid and Its Derivatives. ACS Catal. 2015, 5, 6529-6544. [CrossRef]

29. Taarning, E.; Nielsen, I.S.; Egeblad, K.; Madsen, R.; Christensen, C.H. Chemicals from Renewables: Aerobic Oxidation of Furfural and Hydroxymethylfurfural over Gold Catalysts. ChemSusChem 2008, 1, 75-78. [CrossRef]

30. Signoretto, M.; Menegazzo, F.; Contessotto, L.; Pinna, F.; Manzoli, M.; Boccuzzi, F. Au/ZrO ${ }_{2}$ : An efficient and reusable catalyst for the oxidative esterification of renewable furfural. Appl. Catal. B. Environ. 2013, 129, 287-293. [CrossRef]

31. Menegazzo, F.; Fantinel, T.; Signoretto, M.; Pinna, F.; Manzoli, M. On the process for furfural and HMF oxidative esterification over $\mathrm{Au} / \mathrm{ZrO}_{2}$. J. Catal. 2014, 319, 61-70. [CrossRef]

32. Ferraz, C.P.; Zielinski, M.; Pietrowski, M.; Heyte, S.; Dumeignil, F.; Rossi, L.M.; Wojcieszak, R. Influence of Support Basic Sites in Green Oxidation of Biobased Substrates Using Au-Promoted Catalysts. ACS Sust. Chem. Eng. 2018, 6, 16332-16340. [CrossRef]

33. Gyngazova, M.S.; Grazia, L.; Lolli, A.; Innocenti, G.; Tabanelli, T.; Mella, M.; Albonetti, S.; Cavani, F. Mechanistic insights into the catalytic transfer hydrogenation of furfural with methanol and alkaline earth oxides. J. Catal. 2019, 372, 61-73. [CrossRef] 